\title{
Analysis of losses in the mixing section of the central air conditioner using the entropy-statistical method
}

\author{
M.I. Zdobnov ${ }^{(\text {a) }}, N . A$. Lavrov $^{(b)}, V . V$. Shishov ${ }^{(b)}$ \\ (a) "ACES CONSULTING" LLC \\ Moscow, 109004, Russia, zdonov_m@mail.ru \\ (b) Bauman Moscow State Technical University \\ Moscow, 105005, Russia, lavrovna@bmstu.ru
}

\begin{abstract}
The article presents an entropy-statistical analysis of losses in the mixing section of a central air conditioner. The temperature and humidity of the outdoor and recirculating air were measured. The methodology for determining losses using the entropy-statistical method is presented in the work. The calculation of losses in the mixing section of the central air conditioner due to the mixing of air flows depending on the flow rate of the supply and recirculation air as well as due to hydraulic losses. A comparative analysis of the results is carried out and the distribution diagrams of the component losses are presented. Proposed conclusions regarding the way to reduce losses.
\end{abstract}

Keywords: central air conditioning, mixing section, air flow, outdoor air, recirculation air, losses, entropy-statistical analysis.

\section{INTRODUCTION}

The central air conditioner with the section of mixing of air streams of external and recirculating air is considered in this article. The schematic diagram of the installation is shown in figure 1.

The central air conditioner consists of: section of filtration of external air and exhaust air, plate recuperator, water heater, air heat exchangers, which are the condenser and evaporator of the built-in cooling machine, section of supply and exhaust fans. Losses in the mixing section of the central air conditioner are considered.

Supply air passes through the air intake section, filtration section, mixing section, recuperator (working only in winter), air heat exchanger, which is the condenser of the cooling machine, air heater, ventilation section. Exhaust air passes through the air intake section, filtration section, ventilation section, recuperator (working only in winter), air heat exchanger, which is the evaporator of the cooling machine, mixing section. 


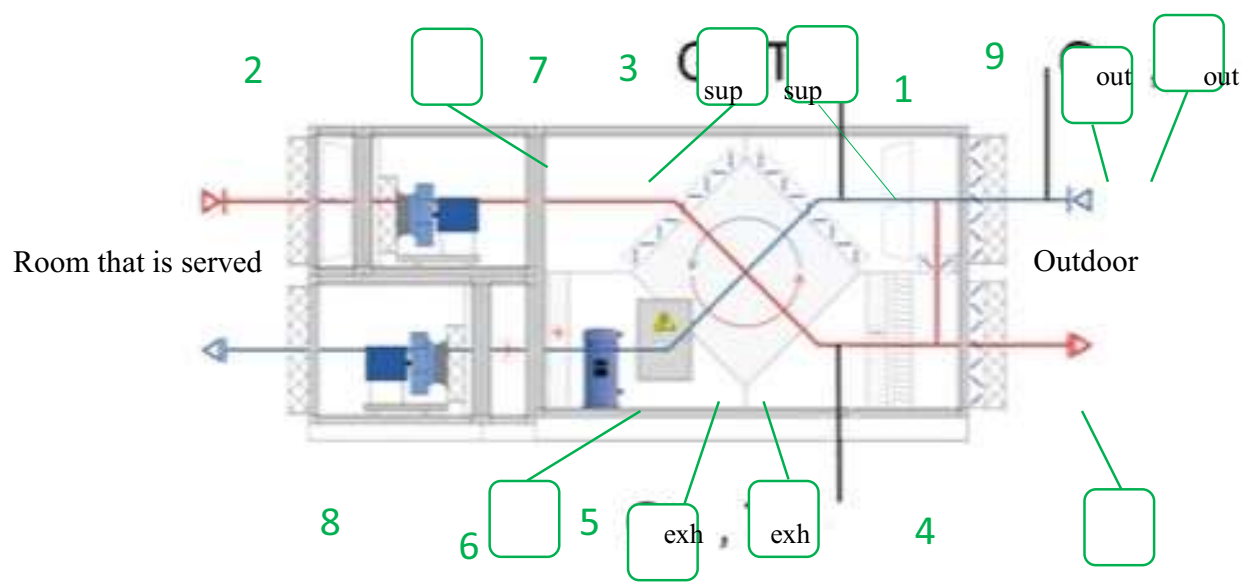

Figure 1. Scheme of the central air conditioner:

1,2 - outdoor and exhaust air filtration sections, 3 - heat exchanger, 4 - evaporator and 5 - condenser integrated chiller, 6 - water heater, 7 - exhaust and 8 - supply fans, 9 - mixing section.

\section{ANALYSIS OF LOSSES IN THE MIXING SECTION OF THE CENTRAL AIR CONDITIONER}

The work expended can be divided into two components:

- minimal (theoretical) work in which processes are possible only theoretically;

- work on compensation of losses due to irreversibility

From the viewpoint entropy-statistical method [1-7] losses are proportional to the entropy production.

According to the Huy-Stodola theorem [1], the loss of energy in the system due to the nonequilibrium processes occurring in it is proportional to the production of entropy in all parts of the system $\Delta S^{\prime}{ }_{i}$

$$
\delta L_{\text {losses }}=T_{0} \cdot \sum_{i=1}^{n} \Delta S_{i}^{\prime},
$$

where $T_{0}$ - ambient temperature. Determination of entropy production in separate parts of the plant allows to select the most energy consuming element of the system and then try to reduce the losses due to irreversibility in this element.

Consider the losses for the mixing section of outdoor and recirculating air flows. Entropy production when two flows mix is defined as the total change in the entropy of the flows:

$$
\begin{gathered}
\Delta S^{\prime}=G_{\text {exh }} \cdot \Delta S_{\text {exh }}+G_{\text {out }} \cdot \Delta S_{\text {out }}= \\
=G_{\text {exh }} \cdot\left(S_{\text {sup }}-S_{\text {exh }}\right)+G_{\text {out }} \cdot\left(S_{\text {sup }}-S_{\text {out }}\right)=
\end{gathered}
$$




$$
=G_{\text {exh }} \cdot c_{p_{\text {exh }}} \cdot \ln \left(T_{\text {sup }} / T_{\text {exh }}\right)+G_{\text {out }} \cdot c_{p_{\text {out }}} \cdot \ln \left(T_{\text {sup }} / T_{\text {out }}\right)
$$

where $\boldsymbol{G}$ and $\boldsymbol{T}$ - mass flow rate and air temperature. The index «exh» refers to the exhaust air, the index «sup» - to the supply air, the index «out» - to the outside air.

The results of measurements of temperature and humidity of air flows at the inlet and outlet of the mixing section of the central air conditioner are presented in Table 1.

The measurements were carried out at intervals of five minutes. The temperature and humidity were measured by an active sensor Carel, type DPDC210000 (specifications are available on the manufacturer's website http://www.carelrussia.com).

\begin{tabular}{|c|c|c|c|c|c|c|}
\hline № & Time & $\boldsymbol{t}_{\text {in }}^{\text {exh }}$ & $\boldsymbol{t}_{\text {in }}^{\text {exh }}$ & $\boldsymbol{t}_{\text {in }}^{\text {out }}$ & $\boldsymbol{\phi}_{\text {out }}^{\text {in }}$ & \% recir. \\
\hline & h:min & ${ }^{\boldsymbol{0}} \boldsymbol{C}$ & $\boldsymbol{\%}$ & ${ }^{\boldsymbol{0}} \boldsymbol{C}$ & $\boldsymbol{\%}$ & \\
\hline 1 & $16: 15$ & 27,9 & 36,8 & 25,0 & 42,8 & $10,0 \%$ \\
\hline 2 & $16: 20$ & 27,8 & 36,8 & 25,3 & 42,8 & $20,0 \%$ \\
\hline 3 & $16: 25$ & 27,6 & 36,9 & 25,6 & 42,7 & $30,0 \%$ \\
\hline 4 & $16: 30$ & 27,3 & 36,9 & 25,8 & 42,7 & $40,0 \%$ \\
\hline 5 & $16: 35$ & 27,1 & 36,9 & 25,9 & 42,7 & $50,0 \%$ \\
\hline 6 & $16: 40$ & 27,0 & 36,8 & 26,0 & 42,6 & $60,0 \%$ \\
\hline 7 & $16: 45$ & 27,0 & 36,8 & 26,0 & 42,6 & $70,0 \%$ \\
\hline 8 & $16: 50$ & 27,0 & 36,8 & 25,5 & 42,5 & $80,0 \%$ \\
\hline 9 & $16: 55$ & 27,0 & 36,8 & 25,0 & 42,5 & $90,0 \%$ \\
\hline
\end{tabular}

Table 1. Part 1

\begin{tabular}{|c|c|c|c|c|c|}
\hline № & Time & $\boldsymbol{L}_{\boldsymbol{e x h}}^{\text {air }}$ & $\boldsymbol{G}_{\boldsymbol{e x h}}$ & $\boldsymbol{L}_{\text {out }}^{\text {air }}$ & $\boldsymbol{G}_{\text {out }}$ \\
\hline & $\boldsymbol{h}: \boldsymbol{m i n}$ & $\boldsymbol{m}^{\mathbf{3}} / \boldsymbol{h}$ & $\boldsymbol{k g} / \boldsymbol{h}$ & $\boldsymbol{m}^{\mathbf{3}} \boldsymbol{h}$ & $\boldsymbol{k g} / \boldsymbol{h}$ \\
\hline 1 & $16: 15$ & 2000 & 2324,4 & 18000 & 21124,9 \\
\hline 2 & $16: 20$ & 4000 & 4650,4 & 16000 & 18757,1 \\
\hline 3 & $16: 25$ & 6000 & 6980,6 & 14000 & 16394,6 \\
\hline 4 & $16: 30$ & 8000 & 9317,5 & 12000 & 14042,3 \\
\hline 5 & $16: 35$ & 10000 & 11655,4 & 10000 & 11697,6 \\
\hline 6 & $16: 40$ & 12000 & 13991,7 & 8000 & 9354,8 \\
\hline 7 & $16: 45$ & 14000 & 16323,6 & 6000 & 7016,1 \\
\hline 8 & $16: 50$ & 16000 & 18655,6 & 4000 & 4686,0 \\
\hline 9 & $16: 55$ & 18000 & 20987,5 & 2000 & 2347,3 \\
\hline
\end{tabular}

Table 1. Part 2 


\begin{tabular}{|c|c|c|c|c|c|}
\hline № & Time & $\boldsymbol{L}_{\text {sup }}^{\text {air }}$ & $\boldsymbol{G}_{\text {sup }}$ & $\boldsymbol{T}_{\text {sup }}$ & $\boldsymbol{\phi}_{\text {sup }}$ \\
\hline & $\boldsymbol{h : m i n}$ & $\boldsymbol{m}^{3} / \boldsymbol{h}$ & $\boldsymbol{k g} / \boldsymbol{h}$ & $\boldsymbol{m}^{3} / \boldsymbol{h}$ & $\boldsymbol{k g} / \boldsymbol{h}$ \\
\hline 1 & $16: 15$ & 20000 & 23448,1 & 25,3 & 42,2 \\
\hline 2 & $16: 20$ & 20000 & 23407,3 & 25,8 & 41,5 \\
\hline 3 & $16: 25$ & 20000 & 23374,6 & 26,2 & 41,0 \\
\hline 4 & $16: 30$ & 20000 & 23359,6 & 26,4 & 40,3 \\
\hline 5 & $16: 35$ & 20000 & 23352,9 & 26,5 & 39,7 \\
\hline 6 & $16: 40$ & 20000 & 23346,3 & 26,6 & 39,1 \\
\hline 7 & $16: 45$ & 20000 & 23339,6 & 26,7 & 38,5 \\
\hline 8 & $16: 50$ & 20000 & 23341,5 & 26,7 & 37,9 \\
\hline 9 & $16: 55$ & 20000 & 23334,8 & 26,8 & 37,3 \\
\hline
\end{tabular}

Table 2. The parameters of the air after mixing

Using the measured parameters, the values of entropy production during mixing of air flows in the central air conditioner are determined using the formula (1), which are presented in Table 3 and Figure 2.

\begin{tabular}{|c|c|c|}
\hline \multirow{2}{*}{ № } & Time & $\boldsymbol{\Delta S}$ \\
\cline { 2 - 3 } & h:min & $\boldsymbol{B m} / \boldsymbol{K}$ \\
\hline 1 & $16: 15$ & 0,31 \\
\hline 2 & $16: 20$ & 0,11 \\
\hline 3 & $16: 25$ & 0,10 \\
\hline 4 & $16: 30$ & 0,06 \\
\hline 5 & $16: 35$ & 0,04 \\
\hline 6 & $16: 40$ & 0,03 \\
\hline 7 & $16: 45$ & 0,03 \\
\hline 8 & $16: 50$ & 0,04 \\
\hline 9 & $16: 55$ & 0,04 \\
\hline
\end{tabular}

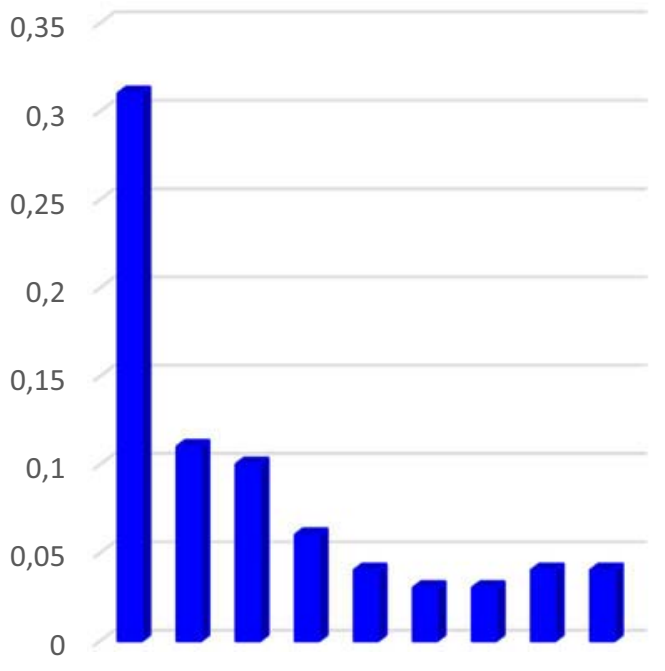

Table 3. Measurement of the the production of entropy upon mixing

Figure 2. The production of entropy upon mixing

In addition to losses associated with the mixing process, there are also hydraulic losses, which are defined as the sum of the friction losses and the local resistance losses.

$$
\begin{aligned}
& \Delta P_{f r}=R_{f r} \cdot l \\
& \Delta P_{\text {localfr }}=P_{\text {dyn }} \cdot \sum \xi
\end{aligned}
$$


where $R_{f r}$ - specific friction losses, $[\mathrm{Pa} / \mathrm{m}]$, defined by

$$
R=\frac{\lambda \cdot v^{2} \cdot \rho}{2 \cdot d_{e q}}
$$

$l$ - the length; $\lambda$ - roughness coefficient, $v$ - linear speed, $\rho$ - density, deq - the equivalent diameter of the channel $\Sigma \xi$ - sum of local resistance coefficients.

The dynamic pressure in the duct is defined as

$$
P_{d y n}=\frac{\rho \cdot v^{2}}{2}
$$

On the other hand, hydraulic losses can be determined through entropy production using dependences for ideal gas [3-4]

$$
\begin{gathered}
\Delta S^{\prime}=G_{\text {exh }} \cdot \Delta S_{\text {exh }}+G_{\text {out }} \cdot \Delta S_{\text {out }}= \\
=G_{\text {exh }} \cdot R \cdot \operatorname{Ln}\left(\frac{P_{\text {exh }}}{P_{\text {exh }}-\Delta P_{\text {exh }}}\right)+G_{\text {out }} \cdot R \cdot \operatorname{Ln}\left(\frac{P_{\text {out }}}{P_{\text {out }}-\Delta P_{\text {out }}}\right)
\end{gathered}
$$

Entropy production due to hydraulic losses using the measurement results and formulas (3) are presented in table 4 and figure 3.

\begin{tabular}{|c|c|c|}
\hline \multirow{2}{*}{ № } & Time & $\boldsymbol{\Delta S}$ \\
\cline { 2 - 3 } & h:min & $\boldsymbol{B} \boldsymbol{m} / \boldsymbol{K}$ \\
\hline 1 & $16: 15$ & 75,95 \\
\hline 2 & $16: 20$ & 88,13 \\
\hline 3 & $16: 25$ & 100,42 \\
\hline 4 & $16: 30$ & 112,86 \\
\hline 5 & $16: 35$ & 125,36 \\
\hline 6 & $16: 40$ & 137,85 \\
\hline 7 & $16: 45$ & 150,29 \\
\hline 8 & $16: 50$ & 162,78 \\
\hline 9 & $16: 55$ & 175,22 \\
\hline
\end{tabular}

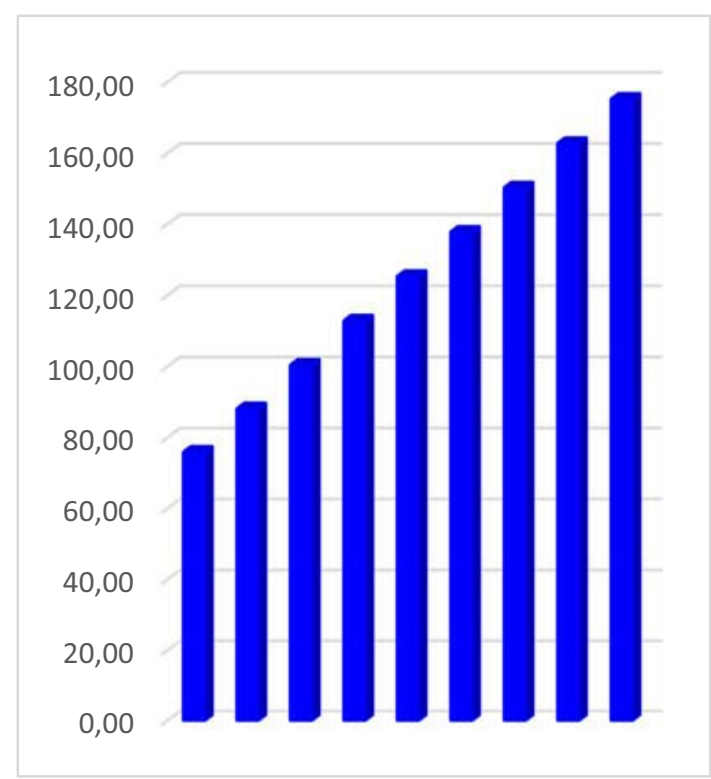

Table 4. Measurement of the entropy production due to hydraulic losses

Figure 3. Entropy production due to hydraulic losses 


\section{CONCLUSIONS}

The entropy-statistical method can be used to estimate losses due to mixing of air flows in the mixing section of the central air conditioner. This method of analysis allows to determine the components of mixing losses.

Analysis of the results shows that the hydraulic losses are significantly higher than the losses associated directly with the mixing of air flows in the central air conditioner section.

The main direction of improving the mixing section of the central air conditioner is to reduce hydraulic losses, which is achieved:

- increasing the useful cross-sectional area of the mixing section;

- minimization of local resistance coefficients in the mixing section.

\section{NOMENCLATURE}

$L \quad$ expended work [J]

$L_{\min } \quad$ minimal (theoretical) work, in which processes are possible only theoretically $[\mathrm{J}]$

$\delta L_{\text {nотери }} \quad$ work to compensate for losses due to irreversibility [J]

$T_{0} \quad$ ambient temperature [K]

$G_{\text {exh }} \quad$ exhaust air flow $[\mathrm{kg} / \mathrm{h}]$

$G_{\text {out }} \quad$ outdoor air flow $[\mathrm{kg} / \mathrm{h}]$

$\Delta P_{m p} \quad$ friction loss $[\mathrm{Pa}]$

$\Delta P_{\text {localfr }} \quad$ local resistance losses $[\mathrm{Pa}]$

$\Delta S_{i} \quad$ entropy production in the $\mathrm{i}$-th process $[\mathrm{W} / \mathrm{K}]$

$R \quad$ gas constant $\left[\mathrm{J} / \mathrm{mol}^{*} \mathrm{~K}\right]$

$c_{p} \quad$ heat capacity of air $\left[\mathrm{J} / \mathrm{kg}^{*} \mathrm{~K}\right]$

\section{REFERENCES}

1. Arkharov A.M., Basics of cryology. Entropy-statistical analysis of lowtemperature systems (2014)

2. D.T. Gareeva, N.A. Lavrov, Chem. and Petrol. Eng. 51, № 11-12 (2016)

3. N.A. Lavrov, The results of calculations of energy losses in cooling processes using entropy-statistical analysis when applying temperature averaging and taking into account its changes, Bulletin of Bauman Moscow State Technical University 5 (2008)

4. A.M. Arkharov, V.V. Sychev, Kholodilnaya Tekhnika, Issue № 4 (2007)

5. A.M. Arkharov, About thermodynamic temperature space, heat, cold, exergy and entropy as basic concepts of engineering cryology, Kholodilnaya Tekhnika, Issue № 6 (2009)

6. A.M. Arkharov, Analysis of energy systems in a single thermodynamic temperature field, Chem. and Petrol. Eng. 46, Issue № 1 (2010) 
7. A.M. Arkharov, Some features of low-temperature thermodynamic analysis, Bulletin of Bauman Moscow State Technical University, Issue № S1 (2010)

8. A.M. Arkharov, V.V. Shishov, Kholodilnaya Tekhnika, 7 (2011)

9. V.V. Shishov, M.S. Talyzin, Kholodilnaya Tekhnika, 3 (2015)

10. A.M. Arkharov, V.V. Shishov, M.S. Talyzin, Kholodilnaya Tekhnika, 3 (2016)

11. M.I. Zdobnov, N.A. Lavrov, Kholodilnaya Tekhnika, 8 (2018)

12. M.I. Zdobnov, N.A. Lavrov, V.V. Shishov, Kholodilnaya Tekhnika, 2 (2019)

13. M.I. Zdobnov, N.A. Lavrov, V.V. Shishov, Karakulov S.I., Kholodilnaya Tekhnika, 8 (2019)

14. I.A. Arkharov, E.S. Navasardyan, A.S. Glukharev, Eng. J.: Science and Innovation, Issue №5, 65 (2017)

15. V.V. Shishov, A.I. Verkhovnyy, M.K. Vasiliev, R.R. Sahapov, Kholodilnaya Tekhnika, 5 (2017) 